\title{
RESPECT: The Missing Policy Tool of Welfare Reform
}

Vicki Lens

Truters

$\mathrm{T}$ The dramatic reshaping of welfare in 1996 included an arsenal of policy tools, from time limits, work requirements, and sanctions to work supports, job training and education, and case management services. To deploy these tools, welfare offices have been reconfigured and outside providers, including for profit and nonprofit agencies, enlisted. One policy tool, however, has been conspicuously and persistently absent: respect.

There is a long and persuasive scholarly literature demonstrating the importance of respect, and fairness in general, when citizens' interact with government authorities (MacCoun, 2005; Tyler, 2006; Tyler \& Huo, 2002). As Tyler and others have shown, fair procedures matter to citizens. Being treated with respect and courtesy is an essential element of fairness, along with the ability to tell one's story to an unbiased decision maker. Citizens will accept even unfavorable outcomes if they think they have been treated fairly and well. This holds true among diverse groups of citizens, including the rich and the poor, and across all ethnic groups.

Too often and for too long, welfare bureaucracies have been criticized for treating citizens who apply for aid poorly (Brodkin, 1986; Gilliom, 2001; Handler \& Hasenfeld, 2007; Soss, 2002). In the many interviews I have conducted with welfare participants about their experiences with welfare workers, a consistent theme emerges: They often feel disrespected and demeaned in the welfare center.Even inherently helpful service technologies, such as support services, are often meted out in an environment of distrust and suspicion.

Other policy tools, such as sanctions, are inherently punitive because they rely on the reduction or denial of life-sustaining benefits to induce compliance with work requirements. There are, however, better and worse ways to apply sanctions. One welfare bureaucracy relies on "auto-posting," or the mass and automatic recording of a sanction for every participant who misses a required appointment. Participants are then sent an inelegantly named "failure to comply" notice, giving them an opportunity to explain why they missed the meeting, before an actual sanction is imposed, which also assumes failure before the facts are known. To many participants, this presumption of guilt violates basic principles of fairness and respect.

The degree to which fair and courteous treatment are important to welfare participants is striking. When interviewing participants, I also ask about their positive experiences at the welfare office. The stories they choose to relate are revealing, because they are often about acts of kindness and courtesy. A middle-aged man described an uplifting friendly hello ("Hey, Mr. P! How are you doing? Everything all right?") from a worker no longer assigned to his case. He told me how this worker "is hard to get because he's so popular. Everybody wishes they had someone like him unlike some of the people there who are short with clients." A young woman described how she was approached by a worker as she was waiting on line, concerned that she had been waiting too long. An older woman described a worker who "touched my heart because she was very polite and very compassionate." Another described "feeling, okay, well somebody sees, somebody listened" after a worker took the time to explain a glitch in her case, even though she could not fix it then.These stories, too often depicted as exceptional events rather than routine, demonstrate that participants are concerned not only about their benefits, but also about how those benefits are given.

Welfare bureaucracies have much to gain by focusing more on providing fair and respectful treatment and less on threats and sanctions. Research has demonstrated that the fear of punishment has only a modest effect on compliance with the law (MacCoun, 1993). Rather, respectful and fair treatment are more likely to encourage cooperation and 
compliance. This lesson applies to all walks of life and situations. Whether it is citizens interacting with the police, couples negotiating a divorce settlement, or workers in the workplace, people are more likely to follow the rules - even ones they disagree withand comply with agreements if they believe those agreements have been negotiated or applied fairly (Blader \& Tyler, 2003; Tyler, 2006).

Respectful and fair treatment has other benefits. It can act as an antidote to marginalization and stigmatization (Braithwaite, 1989). Although perceptions of unfair treatment and disrespect trigger anger and resentment (Miller, 2001), fair and respectful treatment can enhance self-esteem and feelings of self-efficacy (Tyler, 2006). In short, a culture of courtesy and a focus on fair treatment are among the most effective policy tools available. They can help transform antagonistic and adversarial welfare interactions into relationships that allow workers and participants to work together to overcome obstacles to self-sufficiency.

More and more, government authorities are recognizing the importance of fair and respectful treatment. As one example, the California court system recently embarked on a project to improve the way citizens are treated in the courts (Judicial Council of California, 2006). Their initiative incorporates all four elements of procedural fairness: respect, voice, neutrality, and trust. Social workers have long known the importance of respect. The values of self-determination and respect for the individual are enshrined in our professional code. It is time for welfare bureaucracies to learn the same; it is not only good values, but also good science. SW

\section{REFERENCES}

Blader, S., \& Tyler, T. (2003). What constitutes fairness in work settings? A four-component model of procedural justice. Human Resource Management Review, 12, 107-126.

Braithwaite, J. (1989). Crime, shame and reintegration. New York: Cambridge University Press.

Brodkin, E. (1986). The false promise of administrative reform: Implementing quality control in welfare. Philadelphia: Temple University Press.

Gilliom, J. (2001). Overseers of the poor: Surveillance, resistance, and the limits of privacy. Chicago: University of Chicago Press.

Handler, J., \& Hasenfeld,Y. (2007). Blame welfare: Ignore poverty and inequality. New York: Cambridge University Press.

Judicial Council of California. (2006). Justice in focus: The strategic plan for California's judicial branch, 2006-2112. (2006). Retrieved from http://www.courtinfo. ca.gov/jc/sp.htm
MacCoun, R. J. (1993). Drugs and the law: A psychological analysis of drug prohibition. Psychological Bulletin, 113, 497-512.

MacCoun, R.J. (2005).Voice, control, and belonging: The double-edged sword of procedural fairness. Annual Review of Law and Social Science, 1, 171-201.

Miller, D.T. (2001). Disrespect and the experience of injustice. Annual Review of Psychology, 52, 527-553.

Soss, J. (2002). Unwanted claims: The politics of participation in the U.S. welfare system. Ann Arbor: University of Michigan Press.

Tyler, T. R. (2006). Why people obey the law. Princeton, NJ: Princeton University Press.

Tyler, T. R., \& Huo,Y. J. (2002). Trust in the law. New York: Russell Sage Foundation.

Vicki Lens, JD, PhD, is associate professor, Columbia University School of SocialWork, 1255 Amsterdam Avenue, NewYork, New York 10027; e-mail:VL2012@columbia.edu.

Original manuscript received January 26, 2009 Accepted February 17, 2009 